\title{
Seasonal credit constraints and agricultural labor supply: Evidence from Zambia*
}

\author{
Günther Fink \\ B. Kelsey Jack \\ Harvard School of Public Health \\ Tufts University \\ Felix Masiye \\ University of Zambia
}

February 25, 2014

\begin{abstract}
Small-scale farming remains the primary source of income for a majority of the population in developing countries. While most farmers primarily work on their own fields during the cropping season, off-farm labor activities are common. A growing literature suggests that these off-farm labor activities are often driven by short-term consumption needs and absent credit markets, rather than being the result of optimal farm labor allocation. We conduct a field experiment in rural Zambia to study the interactions between credit availability and household labor decisions. We find that providing households with access to credit substantially alters the allocation of household labor, with households randomly selected for a seasonal loan program selling 25 percent less labor off-farm, on average. We also find that increased credit availability is associated with local increases in wages. Our results suggest that a substantial fraction of rural labor supply is driven by short-term constraints, and that access to credit markets may improve labor allocation efficiency overall.
\end{abstract}

${ }^{*}$ Preliminary draft. Please do not cite without permission. We are grateful to the International Growth Centre and the Agricultural Technology Adoption Initiative (JPAL/CEGA) for financial support and to Innovations for Poverty Action for logistical support. Austin Land and Chantelle Boudreaux provided excellent assistance with the field work and data, respectively. We thank audiences at University of Cape Town SALDRU, the Harvard Development faculty retreat and IGC Growth Week for the many useful comments and suggestions. 


\section{Introduction}

In Zambia, like in much of Sub-Saharan Africa, agriculture employs the vast majority of the rural population, but generates little profit for the average farming household. ${ }^{1}$ A lack of irrigation combined with a long dry season means that harvest incomes arrive only once per year, and must cover household needs for the subsequent 10-12 months. While both wages and labor supply are endogenously determined in the local labor market and thus reflect seasonal differences in the marginal product of labor on and off the household farm, a substantial literature suggests that household labor allocation reflects a coping strategy rather than income maximization (Kochar 1999; Frankenberg et al. 2003; Halliday 2012). The logic of the underlying argument is simple: since most small scale farmers have limited resources and virtually no access to short-term credit, the only way to finance short-term consumption is to generate wage income from local labor markets regardless of whether the wage earned exceeds the marginal product of labor on the household farm. To the extent that farmers can anticipate such future constraints, production plans can be adjusted ex-ante. In many settings, the production plan chosen in the constrained environment will likely not be the same as the optimal choice under an unconstrained environment (Rosenzweig and Binswanger 1993), so that average net incomes achieved by farms will be suboptimal. These welfare losses associated with credit constraints will be further increased by unanticipated shocks to productivity or liquidity needs (Kochar 1995, 1999; Rose 2001; Ito and Kurosaki 2009). If farms have neither access to credit nor sufficient reserves, short-run consumption needs will drive households to sell additional labor off-farm. ${ }^{2}$

While off-farm labor by small-scale farmers is very common in practice, ${ }^{3}$ relatively little is known about the degree to which the provision of short-term off-farm labor is the result of short-term consumption constraints, or the degree to which household labor allocation responds to a change in credit availability. To address these questions, we implemented a field experiment in rural Zambia. As shown in Figures 1 and 2 off-farm casual labor

\footnotetext{
${ }^{1} \mathrm{~A}$ recent study in the region of proposed research shows average income for a family of six of less than US\$ 500 per year (Fink and Masiye 2012). Once capital input, land and labor costs are considered, profits for many of these families may be negative.

${ }^{2}$ A sociological literature suggests that off farm-labor supply in Sub-Saharan Africa is generally not part of the income maximizing strategy of farming households, but rather a coping or "emergency" strategy employed by financially distressed households to satisfy short-term financial or consumption needs in the absence of functioning credit markets (Kerr 2005; Bryceson 2006; Orr et al. 2009; Michaelowa et al. 2010; Cole and Hoon 2013).

${ }^{3}$ For example, in our study setting, 40 percent of households report casual day labor during the previous agricultural season.
} 
(locally referred to as "ganyu") and food shortages are common in the study area, with pronounced seasonal patterns. Zambia's climate allows for only one agricultural cycle each year, which is centered around the rainy season from November to April. Harvest takes place in May and June, and generates income that must cover consumption needs until the following year's harvest. Given that some early crops become available in April, food reserves are most scarce from January to March, generally referred to as the "hungry season" by farmers. The experiment directly targeted the hungry season, offering selected small scale farming households access to interest free maize loans to be repaid in kind after harvest, approximately 3 months after the last loan installment was received. The maximum loan size was 3 bags of ground maize, a quantity large enough to cover the consumption needs of an average household over a three-month period. ${ }^{4}$ Treatment intensity was varied at the village level, with a smaller fraction of households receiving loans in partial (as opposed to full) treatment villages.

Demand for the loans was high, with over 90 percent take up among eligible households. Somewhat more surprisingly, the overwhelming majority of farmers were able and willing to repay their loan, with repayment rates well over 90 percent. To assess the impact of loans on local labor markets and labor allocation decisions, we develop a series of predictions through a simple agricultural labor market model, and test them empirically using our experimental data. Consistent with our priors, we find relatively large effects of the loans on off-farm labor supply. In villages where all farmers were eligible for the maize loan, the probability that a household engaged in off-farm labor in the two weeks preceding the survey fell by around 25 percent (11.8 percentage points) and the number of days of ganyu fell by around one-third, with a corresponding (but statistically imprecise) increase in the number of days worked on-farm. The reductions in off-farm casual labor during the hungry season do not appear to be compensated for by a corresponding increase in off-farm casual labor before loan repayments were due. In the month preceding loan repayment, reported off-farm casual labor was also significantly lower in treated villages, and the overall probability of doing any casual labor at any point during the entire agricultural season was 9.1 percentage points lower in the fully treated villages than in the control villages.

We also find sizable shifts in local wage structures. In fully treated villages, the average

\footnotetext{
${ }^{4}$ Households could receive up to 75 kilograms (in $25 \mathrm{~kg}$ bags) of ground "breakfast meal" maize, which they had to repay with 150 kilograms harvested (unground) maize. A 50 kilogram bag of unground maize yields approximately 25 kilograms of ground maize; the market value of the ground maize received and the harvested maize paid back is very similar. Households in the program therefore receive a transfer equal to the value of the interest on the loan. In Section 3, we calibrate the size of the transfer.
} 
wage reported among (the smaller number of) workers engaging in ganyu increased by almost 50 percent immediately following the loan transfers and by 25 to 35 percent over the treatment period. The wage effects were smaller but remain positive in partial treatment villages, where only 50 percent of farmers were eligible for the loan program. We also find substantial declines in reported hunger in treated villages. Specifically, the intention to treat estimates show that in villages where all households were eligible for the loan, the number of meals consumed by the respondent in the 24 hours preceding the survey increased by 11 percent (0.2 more meals) and household members were almost 50 percent (16.5 percentage points) less likely to miss meals due to food shortages in the week before the survey.

For both the consumption and the labor allocation results, the observed effect sizes are smaller in partial treatment villages, with relatively large - but imprecisely estimated spillovers for households whose neighbors receive loans. All of the data collected suggests that these spillovers are not the result of within community sharing or redistribution of resources: we observe no effect of treatment on reported gifts, loans or transfers among eligible or ineligible households. Given the large wage responses, some positive spillovers through the labor market seem plausible, if ineligible households were likely able to meet their consumption needs with fewer hours of off-farm labor.

A large literature in development economics documents the often complex and seasonal nature of rural labor supply labor (see Rosenzweig 1988). ${ }^{5}$ A number of previous studies have investigated households' use of off-farm labor to smooth consumption in response to (or anticipation of) productivity shocks (Kochar 1995, 1999; Rose 2001; Ito and Kurosaki 2009). One of the central aspects of this interaction is the effect of demand and supply side shocks on agricultural wages. Consistent with the findings in this paper, Jayachandran (2006) shows that incomplete credit markets lower the elasticity of labor supply, further increasing wage volatility. Mobarak and Rosenzweig (2014) show that wage volatility is reduced and sizable welfare improvements are possible when workers can be insured against aggregate shocks.

\footnotetext{
${ }^{5}$ More recently, a growing number of field experiments examine labor supply determinants in developing country settings, some of which shed light on questions of seasonality and consumption constraints. For example, Goldberg (2013) finds very low labor supply elasticities during the low agricultural demand season in Malawi. Also in Malawi, Guiteras and Jack (2014) examine labor supply across the low and high agricultural labor demand seasons and observe that workers have higher earnings opportunities during the high labor demand season, which coincides both with the period of greatest liquidity constraints and the highest returns to labor on the household land. Bryan, Chowdhury and Mobarak (2013) examine short run seasonal labor migration in Bangladesh and find that credit market failures and highly uncertain returns to investment keep long-distance labor supply below welfare-maximizing levels. In a nonagricultural setting, Dupas and Robinson (2014) rule out consumption constraints as a driver of labor supply decisions in their study of reference dependent labor supply among bicycle taxis in Kenya.
} 
The results in this paper are also linked to a larger literature on consumption smoothing. In the face of missing credit markets consumption smoothing strategies are clearly not limited to off-farm labor, and range from livestock and asset sales to migration (for summaries of the literature, see Morduch (1995) and Besley (1995)). The substantial increase in consumption that we observe among treated households suggests that consumption smoothing in our setting is imperfect, i.e. that farms are not able to fully cover their consumption needs through off-farm activities in the absence of credit. These results are also consistent with a long literature that suggests that farmers' constrained nutritional intake is not optimal, and that production can be increased through nutritional improvements (Pitt and Rosenzweig 1986; Strauss 1986; Behrman et al. 1997), with recent evidence provided by Schofield (2013). Given the extreme seasonality of income in agricultural markets, consumption smoothing needs may also be seasonal, ${ }^{6}$ yet few studies have examined the impact of explicitly seasonal transfer or loan programs. Burke (2014) offered farmers in Kenya a loan product that allowed them to exploit seasonal variation in maize prices and finds significant effects on total maize revenues and household expenditures. More similar to our study, Basu and Wong (2012) study a seasonal food credit program in Indonesia and find that food loans increase consumption during the lean season, but do not analyze labor supply impacts. To the best of our knowledge, this is the first study to directly estimate the causal effect of credit constraints on household labor allocation decisions and the resulting local labor market outcomes.

The paper proceeds as follows. In the next section, we present a simple model of agricultural labor decisions in the presence of credit constraints. Section 3 describes the study context, experimental design and implementation. Section 4 sets up the identification strategy and 5 presents the results, and Section 6 concludes.

\section{Conceptual framework}

Consider a simple model of agricultural production, where rational farming households maximize total household income subject to a consumption constraint. Consistent with our empirical setting, we assume that land endowments are fixed, and that there are two types

\footnotetext{
${ }^{6}$ The relationship between income seasonality and consumption smoothing is a topic of some debate. Some evidence suggests that precautionary savings are sufficient to smooth consumption even if income is highly seasonal (Paxson 1993; Chaudhuri and Paxson 2002), yet many developing country settings experience a distinct lean or hungry season (Dercon and Krishnan 2000; Khandker 2012) during which consumption falls. We document seasonal consumption patterns in our study setting in Figure 2.
} 
of farms: large scale commercial farms, which have relatively large capital and land endowments, and hire labor according to their needs, and small scale farms, which divide their labor between their own farm and work on commercial farms at a locally determined wage rate $w$. Large scale farms choose their labor demand optimally to maximize profits such that

$$
Y_{c}^{\prime}\left(l_{c}^{*}\right)=w
$$

where $Y_{c}^{\prime}(l)$ is the marginal product of labor on the commercial farm, with $Y^{\prime \prime}(l)<0$, and $w$ is the local wage rate. Small scale farmers have their own land, and can either sell their labor to the larger (commercial) farms, or work on their own farm. We assume that small scale farmers have a fixed labor endowment $L$ and know the marginal product of their labor on their own land $Y_{s}^{\prime}(l)$; for simplicity, we assume that $Y_{s}^{\prime}(0)=\infty, Y_{s}^{\prime}(L)=0$, so that small scale farmers will always spend a non-zero fraction of their time on their own land, and provide some labor for other farms as well as long as the offered wages are non-zero. Small-scale farms have a fixed minimum consumption requirement $c$ which needs to be either financed with credit $B$, prior savings $k$ or period specific wage income, such that

$$
c \leq l_{o} w+k+B
$$

where $l_{o} w$ is off-farm labor income of households (labor supplied off-farm minus hired labor), $k \geq 0$ are savings and $B \geq 0$ is the maximum amount the farmer can borrow.

\section{Unconstrained Equilibrium}

In the absence of credit constraints, small scale farmers will maximize their income subject to their human resource constraint:

$$
l_{s}+l_{o} \leq L
$$

It is easy to see that farmers will choose their on farm labor such that

$$
Y_{s}^{\prime}\left(l_{s}^{*}\right)=w
$$

so that $l_{o}^{*}=L-l_{s}^{*}$.

The equilibrium wage $w^{*}$ will simply be determined by the intersection of the aggregate labor demand and supply function, i.e. $w^{*}$ is such that 


$$
\int l_{o}^{*}\left(w^{*}\right) d c=\int l_{c}^{*}\left(w^{*}\right) d s,
$$

where the left-hand side of equation (5) integrates over all commercial farmers $c$ and the right hand side of the equation (5) integrates over all small-scale farmers $s$.

\section{Constrained Equilibrium}

Let us define a farm as credit constrained if the farm is not able to cover basic consumption needs with the first-best labor allocation choice, i.e.

$$
c>l_{o}^{*} w+k+B
$$

As outlined in the introduction and shown in further detail below, borrowing options in the study settings are limited, so that one could assume $B=0$ for a large fraction of farmers.

Proposition 1: The total amount of ganyu labor provided in equilibrium increases with the fraction of small-scale farmers who are credit constrained, while the wages observed in equilibrium decline.

The intuition of the proposition is straightforward. In the absence of financing options, the only option farmers have to satisfy their consumption constraint is to increase ganyu labor supply $\left(l_{o}>l_{o}^{*}\right)$. The larger the number of farmers who are credit constrained, the larger the additional labor supply will be; since we assume that the size of large scale farms does not change, this will lower wages in equilibrium. Consider instead an increase in credit availability. First, if the inequality in equation (2) binds, as $B$ increases, $l_{o}$ falls as long as the interest rate on borrowing is sufficiently low. Thus, the direct effect of relaxing credit constraints occurs via the consumption constraint. Second, according to Proposition 1, an increase in credit availability increases wages, which has both an income and a substitution effect. The income effect can be seen in equation (2), where an increase in $w$ lowers $l_{o}$ if the inequality binds. The substitution effect can be seen in equation (4) where an increase in $w$ increases $l_{o}$. The increase in wages thus will partially offset the labor supply adjustments triggered by the increased credit availability.

This stylized model clearly abstracts from a variety of other relevant mechanisms, including the effect of relaxing consumption constraints on labor productivity (Strauss 1986; 
Pitt et al. 1990; Subramanian and Deaton 1996; Strauss and Thomas 1998), and the effect of credit availability on other consumption smoothing strategies and investment choices (Rosenzweig and Wolpin 1993; Morduch 1995; Karlan et al. 2014). Nevertheless, the model generates several clear predictions, which we explore in our empirical analysis. Specifically, we will analyze the impact of increasing credit availability on both farm and village level outcomes. In a friction-free labor market, general equilibrium effects should be observable at the regional or national level. In the local study context, however, mobility is severely limited by poor road infrastructure and a lack of transportation options. In our main wage models, we thus consider each village as a separate labor market. In a friction-free labor market, general equilibrium effects should be observable at the regional or national level. In the local study context, however, mobility is severely limited by poor road infrastructure and a lack of transportation options. In our main wage models, we thus consider each village as a separate labor market.

\section{Context and experimental design}

The study was implemented over the course of a year in Chipata District in Eastern Zambia. Chipata district is located at the southeastern border of Zambia, with an estimated population of 456,000 in 2010 (Zambia 2010 census). Approximately 100,000 people live in Chipata town, the district capital; the remaining population lives in rural areas, with small-scale farming as primary source of income. According to the 2010 Living Conditions and Measurement Survey, rural households in Chipata are on average poorer than in the rest of the country, with $47 \%$ of household classified as "very poor" in the district overall, and $63 \%$ of households classified as very poor in the rural parts of Chipata. Average monthly expenditure of rural households is about one third of the national average, and access to electricity and piped water close to zero in rural areas (see Appendix table A.1 for a summary of differences between Chipata and the rest of Zambia).

\subsection{Study sample}

The study sample is drawn from villages in Chipata district that contain between 15 and 25 small scale farmers and no more than a total of 35 households, using the Zambian Ministry of Agriculture definition of small scale as owning fewer than five hectares of land. Working from the Ministry's registry of farmers in Chipata District for 2011, we first eliminated villages 
with too many or too few listed farmers, then eliminated peri-urban villages and those over one day's drive from the main town. The remaining eligible villages were visited by study enumerators who conducted a listing of farming households. Based on the listing visits, further villages were eliminated if they could not be reached during the rainy season or if the number of households or the size of landholdings contradicted the Ministry's records. ${ }^{7}$ This resulted in the elimination of an additional 8 villages. Household-level eligibility was further restricted to small scale farms with at least one hectare of land. ${ }^{8}$

\subsection{Experimental design and implementation}

We study the effects of a short run, interest-free loan on household labor allocation. The loan was offered to households in January 2013. Under the loan program, eligible households could obtain one 25 kilogram bag of ground maize flour in each of three months during the hungry season (January, February and March), which they were instructed to repay at harvest (June) in the form of (unground) maize. ${ }^{9}$ Figures 1 and 2 show how the treatment timing coincides with periods of off-farm casual labor and household food shortages. While off-farm labor is common in December, food shortages rise dramatically beginning in January, suggesting that off-farm labor driven by consumption constraints peaks in January and February. It is important to note that Zambia has a heavily controlled maize sector, with government intervention through both floor prices on harvested maize (and demand guarantees) and ceiling prices on ground maize. Though maize prices tend to be lower at harvest, the government intervention limits the seasonal fluctuations in maize prices that are observed in neighboring countries, though year-to-year variation remains substantial (see Appendix figure A.1).

We varied the treatment intensity of the loan program at the village level. In 25 percent

\footnotetext{
${ }^{7}$ By dropping households more than one day's drive from the main town and those inaccessible during the rainy season, we potentially eliminate some of the more vulnerable households. While this potentially detracts from the external validity of the results, randomization is conditional on eligibility so sample selection is orthogonal to treatment assignment.

${ }^{8}$ Households with less than one hectare were excluded because of concerns about their ability to repay the loan.

${ }^{9}$ The lack of formal lending institutions and clear market prices make it difficult to estimate the implied interest rate associated with the loan. The value of three bags of maize flour to the farmers was around 135 $\mathrm{KR}$ at market prices in January and the value of three bags of maize at harvest was between $150 \mathrm{KR}$ and $195 \mathrm{KR}$ depending on to whom a farmer chooses to sell maize at harvest. At the time of implementation 5 $\mathrm{KR} \approx 1$ USD. Grinding maize into maize flour also carries a transaction cost. A substantial share of maize is milled for own consumption and traded within the village. The size of the transfer implied by the loan is therefore also hard to estimate, but is small relative to the size of the loan itself.
} 
of the study villages, all eligible households were offered the chance to take up the loan. In half of the study villages, households that expressed interest in the loan entered in a lottery, through which half were selected for the loan program, resulting in approximately equal numbers of households with access to the loan program at full and at partial treatment intensity. The final 25 percent of villages served as the control and received no intervention.

The loan offer and within-village lottery were implemented through a village meeting to which all eligible households were invited in advance. At the meeting, study enumerators explained the loan to the assembled participants. Households were given loan forms and told to return them to their village headperson the following day. If the village was assigned to the partial eligibility treatment, households attending the meeting were entered into a lottery during which names of the participant were drawn from a basket by a child unaffiliated with the study. Half as many names were drawn as were added to the basket, resulting in 50 percent treatment relative to the full eligibility treatment arm. Households drawn in the lottery made their participation decisions by returning their loan form to the headperson, as in the full eligibility arm.

Maize flour was delivered to ten different distribution centers to cover the 30 treatment villages during the 2nd half of each of January, February and March. Villages were informed in advance about the time and place of the maize flour delivery and eligible borrowers consisted of those who had turned in their loan forms to their headperson. Because of the difficulty transporting maize flour, some flexibility was allowed in the pick up procedures. Specifically, the national registration (NRC) card for the eligible borrower was needed to obtain the flour, but the borrower did not have to come in person. ${ }^{10}$ In late June and early July, loan repayment was due. Village heads were involved in reminding households to bring their maize for repayment to a central point in the village. Unlike the distribution of maize flour, collection of maize was done at each village. In a couple of cases, loans were repaid late. Further summary statistics on repayment patterns are described in Section 5.

Households were sampled and village-level treatments were assigned using min-max $\mathrm{T}$ randomization (Bruhn and McKenzie 2009). The approach relies on repeated household draws and village-level assignment to treatment and selects the draw that results in the smallest maximum t-statistic for any pairwise comparison across treatment arms. Balance was tested for 13 village and household level variables, as well as geographic blocks, with

\footnotetext{
${ }^{10}$ In a small number of cases, households were allowed to use a note from the village headperson in lieu of a missing NRC card. While no instances of fraud were reported, any fraud in the loan collection process will bias us against seeing a result.
} 
results described in Section 4.

\subsection{Data}

We rely on both survey and administrative data in our analysis. Survey data comes from three sources: (i) a baseline survey conducted before the start of the agricultural season in October 2012, (ii) a midline survey conducted between the second and third maize delivery in February and March 2013, and (iii) an endline survey conducted after harvest but before repayment in June 2013. We collect data on a host of household and farm characteristics at baseline and endline, and focus the midline survey on labor allocation in the two weeks preceding the survey. An effort was made to keep data collection independent of the intervention, to minimize the role of experimenter demand in influencing survey responses.

\section{Identification}

To evaluate the effect of the maize loan we estimate:

$$
y_{i v t}=\alpha+\beta_{1} \text { full }_{v}+\beta_{2} \text { partial }_{v}+\delta_{t}+u_{i v t}
$$

where $y_{i v t}$ is an outcome of interest for household $i$ located in village $v$ and month $t, f u l l_{v}$ indicates that the village was assigned to the full eligibility treatment, partial $_{v}$ indicates that the village was assigned to the partial eligibility treatment, and $\delta_{t}$ are month dummies to capture seasonal effects. Errors are clustered at the level of the randomization unit, the village $v$, throughout. We include all households in our estimation of equation (7), regardless of take up. The coefficient $\beta_{1}$ therefore captures the effect of being a small scale farmer in a village assigned to the full eligibility treatment, for both takers and non-takers. The coefficient $\beta_{2}$ captures the average effect of being in a partial eligibility village, regardless of lottery outcome and take up decision. In much of the analysis, we pool across months or analyze self-reported behavior in the month of the midline survey only.

Since a household's eligibility in the partial treatment villages depends on the lottery outcome, which was randomly assigned, we can also estimate the reduced form effect of being eligible for a loan on outcomes of interest. ${ }^{11}$ We estimate:

\footnotetext{
${ }^{11}$ For consistency, we define eligibility in both the full and the partial treatment villages conditional on attending the informational meeting. An alternative definition of eligibility, which we will examine in robustness checks, includes all households in both partial and full treatment villages that did not attend the loan meeting.
} 


$$
y_{i v}=\alpha+\text { seligible }_{i}+u_{i v}
$$

where the coefficient $\delta$ represents the average effect of eligibility for the loan across treatment intensities. This specification may be invalid in partial eligibility villages if there are spillovers across households. To empirically test the relevance of spillovers, both as an outcome of interest and as a test of the identifying assumptions for equation (8), we interact the eligible $_{i}$ indicator variable with an indicator for being in a partial treatment village.

We can also estimate the average treatment on the treated with an instrumental variable specification that regresses loan take up on randomly assigned eligibility as the first stage:

$$
\text { bags }_{i v}=\alpha+\text { religible }_{i}+u_{i v} .
$$

The second stage recovers the re-scaled coefficient on the number of bags of maize picked up by the household under the program

$$
y_{i v}=\alpha+\theta b a g s_{i}+u_{i v}
$$

where $\theta$ describes the marginal effect of an additional bag of maize among those who retrieved any bags. Since the instrument is binary and the number of bags ranges from one to three, we recover the effect of an additional bag, on average, on the treated.

\subsection{Balance}

The treatment coefficients $\left(\beta_{1}, \beta_{2}, \delta\right.$ and $\left.\theta\right)$ measure the causal effect of the loan under the identifying assumption that assignment is orthogonal to $u_{i v}$. Table 1 presents the means and standard deviations for control villages (column 1) and the coefficients from a regression of each household characteristic on treatment dummies (columns 2 and 3), with standard errors clustered at the village level. The significance of the coefficient represents the test of the characteristic mean against that in the control, while column 4 shows the p-values from a test that the treatment coefficients are equal.

A few of the summary statistics in Table 1 are worth noting. Household heads are around 46 years old and just under 25 percent are female. Households contain around 5.5 members, with around one child under 5. In the previous season, households produced 1.3 acres of local maize, 0.97 acres of hybrid maize and 1.7 acres of cotton on average, and used a total of 4.8 acres for agricultural production. Households engaged in around 12 days of casual labor 
(ganyu) in the last season and hired around 4 days of ganyu. The average household stored 25 bags of maize after the previous harvest and had a baseline harvest value of around 484 USD. In general, household characteristics are well balanced, with 5 out of 39 pairwise tests significant at $p<0.10$, which is just above what we would expect from normal sampling with a 10 percent significance threshold. Most notably for our analysis, households in the full treatment villages engaged in marginally significantly fewer days of casual labor in the previous season than did households in the partial treatment villages. We control for these characteristics throughout our analysis.

\subsection{Attrition and selection}

The main identifying assumption of our empirical analysis would be violated if households select into eligibility status or drop out of the loan program differentially across treatments. Households could exit the study both during the midline survey and the endline survey. Overall attrition rates are low as shown in Table 2. The table reports means and standard deviations at baseline in column 1 and the coefficients from a univariate regression of the binary attrition or selection outcome on each explanatory variable with standard errors clustered at the village level. Each coefficient therefore reflects a separate regression. A total of 439 households were enrolled into the study at baseline; 98 percent of which were in the midline and endline surveys. Importantly, the probability of being in the midline and endline surveys is not affected by treatment status (columns 2 and 4).

Among households assigned to treatment, attrition could also occur at the stage of the loan meeting, which took place in each partial and full treatment village. Column 3 of Table 2 shows the probability of of attending the loan meeting as a function of each household characteristic (again, each coefficient is its own regression), conditional on residing in a treatment village and being in the baseline sample. Among eligible households, the probability of attending the loan meeting is increasing in the age of the household head and land size, but is not significantly affected by treatment intensity.

\section{Results}

We begin with descriptive statistics associated with take up and repayment of the loan, and a general manipulation test for changes in consumption, then move on to the analysis of impacts on labor supply. Next we investigate the equilibrium effect on wages, as described 
in the conceptual framework (Section 2). We conclude our analysis with suggestive results on treatment spillovers within village.

\subsection{Take up and repayment}

Table 3 summarizes take up rates by treatment intensity. In the partial treatment villages, a total of 221 households were surveyed at baseline. 208 households participated in the information session, and 104 households were eligible to participate in the loan program through a public lottery. All of the selected households decided to enroll in the loan program. Out of 104 households in the fully treated villages, 99 households came to the loan information session, and 90 households (91 percent) decided to sign up for the loan program. On average, households picked up 2.79 in the partial treatment group (among eligible households), and 2.62 in the full treatment group. The high take up rate that varies little with treatment intensity means that, in practice, equation (8) delivers estimates that approximate the average treatment effect on the treated. Though take up rates vary slightly with treatment intensity, they are not predicted by any of the household characteristics presented in Table 1.

The bottom of Table 3 shows repayment rates, which were very high in both groups. Around $98 \%$ of participants partially repaid, and $95.2 \%$ and $97.7 \%$ fully repaid their loans in the partial and full treatment villages, respectively. Though not shown, repayment rates are significantly increasing in households financial resources as measured by past harvest yields, the quantitive of ganyu hired and maize reserves.

\subsection{Consumption}

As a first step towards identifying the impact of the loan programs on household consumption and labor allocation we analyze food consumption. As described above, we conducted a midline survey in the middle of the hungry season, during which detailed information on food intake was collected. Maize is not only the most commonly grown crop in this area, but also - in the form of maize porridge ("nshima") the most commonly consumed food item in the region, with most well-off households consuming nshima three times a day. To assess changes in nutrition, we examine two summary measures of food consumption: the number of times the respondent reported eating nshima during the 24 hours preceding the interview, and whether any family member had to skip a meal in the week preceding the interview because of food shortages. In the control group, the average respondent consumed maize meal 1.74 times in the 24 hours preceding the interview, and 36 percent report that a family 
member had to miss a meal.

Table 4 shows the corresponding treatment effects. In full treatment villages, respondents consumed 0.2 more meals, an increase of 11 percent in eating frequencies over the control group. The increase in the partial treatment villages was smaller and not statistically different from consumption in the control. When we analyze the impact of loan eligibility at the household level in column 2, the overall effects appear smaller than the full village treatment effect, but larger than the shifts observed in the partial treatment villages. The number of respondents who report that family members missed meals follows a similar pattern. The treatment effect in the full treatment villages shows a 16.5 percentage point decline (a 45 percent reduction relative to the control group), but a statistically insignificant effect in the partial treatment villages. The individual ITT is once again in between the partial and full treatment village impact.

\subsection{Labor supply}

We begin our analysis of labor supply effects with the midline survey. The main advantage of the midline survey is that labor activity reports were restricted to a two-week period (limiting recall issues), and that the timing of the survey (conducted in the last week of February and first week of March of 2013) allows us to directly investigate labor shifts in the middle of the hunger season, i.e. the most constrained part of the agricultural season.

Panel A of Table 5 shows the village level intention-to-treat results for farm labor supply. Given the small sample size, we include a full set of household characteristics are used as controls in all specifications. In column (1) we analyze a binary indicator for whether the household engaged in any off-farm ganyu labor activities in the two weeks preceding the midline survey. In the two-week period preceding the survey, $46 \%$ of households in the control group indicated that they provided ganyu labor on other farms, which is substantially larger than the monthly averages reported in Figure 1. In full treatment villages, this proportion was reduced by 11.8 percentage points (25\%), while the reduction in partial treatment villages was 7.6 percentage points $(16.5 \%)$ and imprecisely estimated. Days of ganyu also decrease following a similar pattern, though the treatment effect in the partial treatment villages is close to zero. While we find positive point estimates for labor supply on the the household farm in both groups (column 3), the confidence intervals are large and the effects are not statistically significant. Finally, we observe no detectable change in hiring of outside labor (column 4). 
In Panel B, we show the intention-to-treat results at the household level. The results look similar to Panel A: the estimated coefficient on ganyu provision (column 1) suggests an average reduction in ganyu labor of 8 percentage points. Since we now also include non-eligible households in partial treatment areas (who may have benefitted from the intervention) in the comparison category, the slightly smaller coefficient could in theory be evidence for spillover effects in these villages. At the household level, neither days of ganyu nor days on farm (columns 2 and 3) are precisely estimated. Panel C shows IV (LATE) effects. Because of the extremely high take up rate, the results are virtually identical to the results presented in Panel B, but scaled to a per-bag coefficient, according to the number of bags of maize borrowed by eligible households.

While the midline data covers a short recall period and is therefore less prone to measurement error or recall biases than the endline data, the full-season recall data on labor collected as part of the endline survey allows us to investigate whether households compensated for lower rates of ganyu during the hungry season with an increase before loan repayments were due. Table 6 shows results from the endline data, covering the full agricultural calendar, that are qualitatively similar to the midline results in column (1) of Table 5. Loan participants did not experience an increase in off-farm labor around the harvest. The table also reports days of hired ganyu, which shows large and positive (around a 46 percent increase over the control mean in the full treatment villages) but imprecisely estimated treatment effects. Because these measures also include the months preceding the loan offer, we place additional weight on the recall reliability of the endline responses in Appendix table A.2 that repeats the analysis restricted to the months during which households had loans. Perhaps due to measurement error, estimates are less precise but directionally consistent.

In Figure 3 we conduct an analysis that leans heavily on household recall reliability for the labor supply data collected at baseline and endline to show the changes in labor supply to show the month specific treatment effect with 90 percent confidence intervals. We plot the interaction term of household eligibility with month dummies in a model with household fixed effects. While no differences are apparent in the 2011/12 season (as reported in the baseline survey), the average likelihood of providing ganyu labor declines towards the end of the study. The largest reductions are visible for January and May, corresponding to the month immediately following the start of the loan, when households are very food constrained, and the peak month of harvest when off-farm ganyu is readily available. The fact that treatment effects persist through the month preceding the loan repayment (which was due in June) suggests that treated households do not have to engage in ganyu to fulfill 
their loan obligations.

\subsection{Wages}

As outlined in our theoretical framework, changes in ganyu labor participation should have no (or only marginal) effects on labor market wages if labor markets were frictionless. As we have argued above, frictions in the rural labor markets are substantial, with most short-term labor exchanges occurring within walking distance of the household farm. To test whether an increase in credit availability led to a local increase in wages, we start by analyzing wages reported by households in the midline survey. As part of the midline survey, households were first asked to report the total number of person-days of ganyu provided in the 2 weeks prior to the survey, and then asked to report total ganyu income for the household in total, as well the days of ganyu worked and income earned by each household member. We start our analysis by looking at the average wage reported at the household level: the total ganyu income divided by the total number of person-days reported. Two things are worth highlighting: first, the duration of a typical ganyu work day varies substantially; the wage number calculated should thus be interpreted as the wage income a worker receives for a typical day of ganyu. Second, there is a substantial fraction of households not doing any ganyu, for which this variable is not defined - wages thus do not represent wage offers, but only wage offers accepted. Panel A of Table 7 shows that average wage rates reported at midline were around KR 9.65, which corresponds to slightly less than 2 USD at current exchange rates. In column 1 we regress reported wages on the two treatment arms; in column 2 we use the fraction of farmers eligible for the program at the village level. Independent of the chosen specification, the magnitude of the observed effect is large, suggesting an increase of local wages of up to 49 percent. The analysis is repeated in columns 3 and 4 , using reported wages for each individual in the household who did ganyu. The individual specific wage is lower, on average, and the treatment effects are less precisely estimated, perhaps because of the greater selection into the labor market observed in the individual level analysis.

In the baseline and endline surveys, households were also asked to indicate the total number of person-days worked off-farm. For this longer-term recall module, households were asked to separately report off-farm labor activities for each of the four main parts of the agricultural season: field preparation, planting, weeding, and harvesting. For each activity, respondents indicated the total number of (full-time) person-days for each activity, as well as the total remuneration, including food as well as other in-kind services. As Panel B of Table 
7 shows, the average wage of KR 18 (US\$ 3.5) was substantially higher at endline than at midline, reflecting on average longer working hours (full days of work), remuneration rates that vary by season and the inclusion of non-cash payments in the wages. In Panel B of Table 7 , we show the results of a basic household panel model, where each observation corresponds to a wage reported in a given season (2011/12 in baseline, 2012/12 in endline) and for a given activity. A total of 1025 ganyu wages were reported across the two seasons. In Panel $\mathrm{B}$ of Table 7 , we show the results from a basic difference-in-difference estimator with village fixed effects, where all activities in the second year are considered treated in villages with loan programs (columns 1 and 2). In columns 3 and 4, we report the results of an alternative specification, where we only consider weeding and harvesting related activities in the second year as treated. Given that the vast majority of ganyu activities fall in this category, the results from the two models appear relatively similar overall. All of the estimated coefficients go in the expected (positive) direction, but none of the coefficients is statistically significant in these models. While the magnitudes of the wage treatment effects are (insignificantly) larger at endline than at midline, relative to the respective control group means, they are smaller (27-35 percent versus 49 percent). This difference in the relative shift is due in part to the higher control group average observed at endline, but also perhaps to a dissipation of the treatment effect and to attenuation due to measurement error in the endline.

\subsection{Within-village spillovers}

The results shown in Sections 5.2 and 5.3 suggest that ITT effects are smaller in partial treatment villages than in the full treatment villages. We next decompose treatment effects in partial treatment villages into eligible and ineligible households to estimate within-village spillovers from the food loans. We hypothesize that spillovers may occur for three reasons. First, eligible households may transfer food to ineligible households in partial treatment villages as gifts. Second, eligible households may hire more ineligible households to do ganyu. Third, general equilibrium wage effects may impact labor allocation decisions of ineligible households in partial treatment villages, as described in Section 2.

Figure 4 and Appendix table A.3 show spillover effects on labor and consumption outcomes and on interhousehold transfers, respectively. First, transfers from eligible to ineligible households did not increase (Appendix table A.3). Note that the elevated level of incoming gifts and loans among eligible households is, presumably, driven by some counting of the loans in that response. Second, ganyu by ineligible households did not increase (panels c 
and d of Figure 4). This suggests that the effects on ineligible households are driven by changes in wages. While we lack the precision to detect spillover effects at conventional levels of significance, Figure 4 shows that ineligible households experience outcomes that move toward the treatment effects and away from the controls for consumption and labor impact. The graphs plot marginal effects from the interaction of household-level eligibility and village-level treatment interactions. A comparison across ineligible households in pure control and partial villages shows the spillover effect on ineligible households of being in a village where some households receive loans. A comparison across eligible households in partial and full treatment households shows the spillover impact on eligible households. In all panels of the figure, the effects are indistinguishable for eligible and ineligible in partial treatment villages. Based on the model developed in Section 2, these spillovers are consistent with income effects that help ineligible households relax their consumption constraints as a result of the decreased share of constrained households in their village.

\section{Discussion and Conclusions}

We implemented a simple and potentially scalable maize loan program in rural Zambia to identify the effect of increased access to seasonal credit on off-farm labor supply. We find that credit access decreases off-farm labor and is associated with an increase in local wages. We also find that increased access to short-term credit increases food consumption, potentially increasing labor productivity both on and off the farm (as in Strauss 1986).

These findings suggest that credit constraints do not only affect consumption choices made by farming households, but also distort farming households' labor allocation decisions. At the mean, our results suggest that households are forgoing around $72 \mathrm{KR}$ of ganyu income as a result of their reallocation away from off-farm labor, which is about half of the value of the maize meal provided to them through the loan. High repayment rates and the lack of observed off-farm labor immediately preceding repayment suggests harvest improvements sufficient to cover the value of the loan. Further research will be needed to examine the extent to which the reallocation of labor resources to farmers' on land can increase the productivity of small scale farmers as well as agricultural production overall. 


\section{References}

Basu, Karna and Maisy Wong, "Evaluating seasonal food security programs in East Indonesia," Mimeo, 2012.

Behrman, Jere R, Andrew D Foster, and Mark R Rosenzweig, "The dynamics of agricultural production and the calorie-income relationship: Evidence from Pakistan," Journal of Econometrics, 1997, 77 (1), 187-207.

Besley, Timothy, Savings, credit and insurance Handbook of Development Economics, North Holland, 1995.

Bruhn, Miriam and David McKenzie, "In Pursuit of Balance: Randomization in Practice in Development Field Experiments," American Economic Journal: Applied Economics, 2009, pp. 200-232.

Bryan, G., S. Chowdhury, and A.M. Mobarak, "Seasonal Migration and Risk Aversion," Mimeo, 2013.

Bryceson, Deborah Fahy, "Ganyu casual labour, famine and HIV/AIDS in rural Malawi: causality and casualty," Journal of Modern African Studies, 2006, 44 (2), 173.

Burke, Marshall, "Selling low and buying high: An arbitrage puzzle in Kenyan villages," Mimeo, 2014.

Chaudhuri, Shubham and Christina Paxson, "Smoothing consumption under income seasonality: Buffer stocks vs. credit markets," Mimeo, 2002.

Cole, Steven M and Parakh N Hoon, "Piecework (Ganyu) as an Indicator of Household Vulnerability in Rural Zambia," Ecology of food and nutrition, 2013, 52 (5), 407-426.

Dercon, Stefan and Pramila Krishnan, "Vulnerability, seasonality and poverty in Ethiopia," The Journal of Development Studies, 2000, 36 (6), 25-53.

Dupas, Pascaline and Jonathan Robinson, "The Daily Grind: Cash Needs, Labor Supply and Self-Control," Mimeo, 2014.

Fink, Günther and Felix Masiye, "Assessing the impact of scaling-up bednet coverage through agricultural loan programmes: evidence from a cluster randomised controlled trial in Katete, Zambia," Transactions of the Royal Society of Tropical Medicine and Hygiene, 2012, 106 (11), 660-667.

Frankenberg, Elizabeth, James P Smith, and Duncan Thomas, "Economic shocks, wealth, and welfare," Journal of Human Resources, 2003, 38 (2), 280-321.

Goldberg, Jessica, "Kwacha gonna do? Experimental evidence about labor supply in rural Malawi," Mimeo, 2013. 
Guiteras, Raymond and B. Kelsey Jack, "Incentives, Productivity and Selection in Labor Markets: Evidence from Rural Malawi," Mimeo, 2014.

Halliday, Timothy $\mathbf{J}$, "Intra-household labor supply, migration, and subsistence constraints in a risky environment: Evidence from rural El salvador," European Economic Review, 2012, 56 (6), 1001-1019.

Ito, Takahiro and Takashi Kurosaki, "Weather risk, wages in kind, and the off-farm labor supply of agricultural households in a developing country," American Journal of Agricultural Economics, 2009, 91 (3), 697-710.

Jayachandran, Seema, "Selling labor low: Wage responses to productivity shocks in developing countries," Journal of Political Economy, 2006, 114 (3), 538-575.

Karlan, Dean, Robert Darko Osei, Isaac Osei-Akoto, and Christopher Udry, "Agricultural decisions after relaxing credit and risk constraints," Quarterly Journal of Economics, 2014, forthcoming.

Kerr, Rachel Bezner, "Informal Labor and Social Relations in Northern Malawi: The Theoretical Challenges and Implications of Ganyu Labor for Food Security," Rural sociology, 2005, 70 (2), 167-187.

Khandker, Shahidur R, "Seasonality of income and poverty in Bangladesh," Journal of Development Economics, 2012, 97 (2), 244-256.

Kochar, Anjini, "Explaining household vulnerability to idiosyncratic income shocks," The American Economic Review, 1995, pp. 159-164.

_ , "Smoothing consumption by smoothing income: Hours-of-work responses to idiosyncratic agricultural shocks in rural India," Review of Economics and Statistics, 1999, 81 (1), 50-61.

Michaelowa, Katharina, Ralitza Dimova, and Anke Weber, "Ganyu Labour in Malawi: Understanding Rural Household's Labour Supply Strategies," Mimeo, 2010.

Mobarak, Ahmed Mushfiq and Mark Rosenzweig, "Risk, Insurance and Wages in General Equilibrium," Mimeo, 2014.

Morduch, Jonathan, "Income smoothing and consumption smoothing," Journal of Economic Perspectives, 1995, 9, 103-103.

Orr, Alastair, Blessings Mwale, and Donata Saiti-Chitsonga, "Exploring seasonal poverty traps: the 'six-week window' in southern Malawi," The Journal of Development Studies, 2009, 45 (2), 227-255.

Paxson, Christina H, "Consumption and income seasonality in Thailand," Journal of Political Economy, 1993, 101 (1), 39.

Pitt, M. M. and M.R. Rosenzweig, Agricultural prices, food consumption and the health 
and productivity of Indonesian farmers, Baltimore: Johns Hopkins University Press, 1986.

Pitt, Mark M, Mark R Rosenzweig, and Md Nazmul Hassan, "Productivity, health, and inequality in the intrahousehold distribution of food in low-income countries," American Economic Review, 1990, 80 (5), 1139-1156.

Ricker-Gilbert, Jacob, Nicole M Mason, Francis A Darko, and Solomon T Tembo, "What are the effects of input subsidy programs on maize prices? Evidence from Malawi and Zambia," Agricultural Economics, 2013, 44 (6), 671-686.

Rose, Elaina, "Ex ante and ex post labor supply response to risk in a low-income area," Journal of Development Economics, 2001, 64 (2), 371-388.

Rosenzweig, Mark R, Handbook of Development Economics, Vol. 1, Elsevier,

- and Hans P Binswanger, "Wealth, Weather Risk and the Composition and Profitability of Agricultural Investments," Economic Journal, 1993, 103 (416), 56-78.

- and Kenneth I Wolpin, "Credit market constraints, consumption smoothing, and the accumulation of durable production assets in low-income countries: Investments in bullocks in India," Journal of Political Economy, 1993, pp. 223-244.

Schofield, Heather, "The Economic Costs of Low Caloric Intake: Evidence from India," Mimeo, 2013.

Strauss, John, "Does better nutrition raise farm productivity?," The Journal of Political Economy, 1986, pp. 297-320.

- and Duncan Thomas, "Health, nutrition, and economic development," Journal of Economic Literature, 1998, 36 (2), 766-817.

Subramanian, Shankar and Angus Deaton, "The demand for food and calories," Journal of Political Economy, 1996, pp. 133-162. 


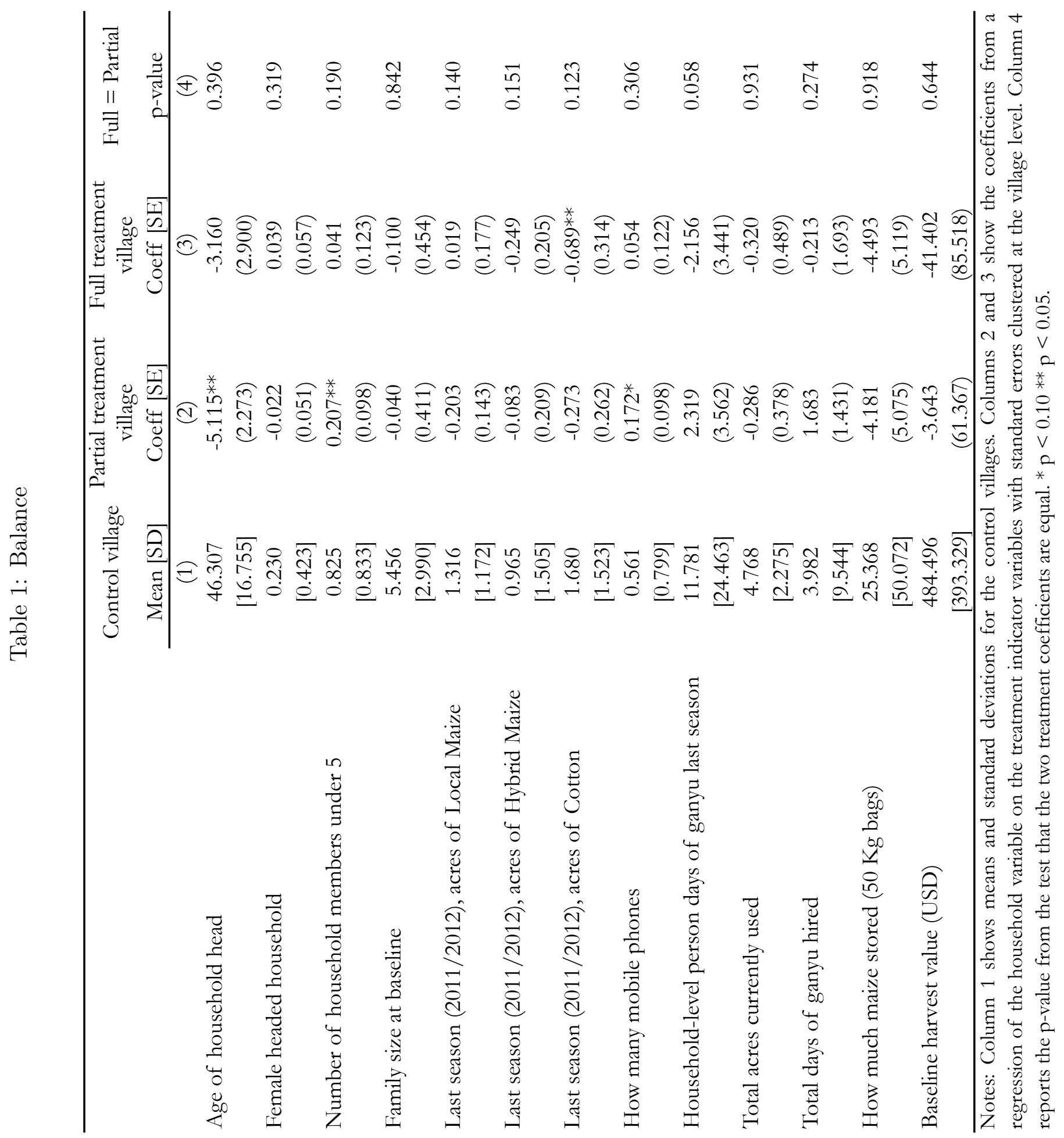


Table 2: Attrition and selection

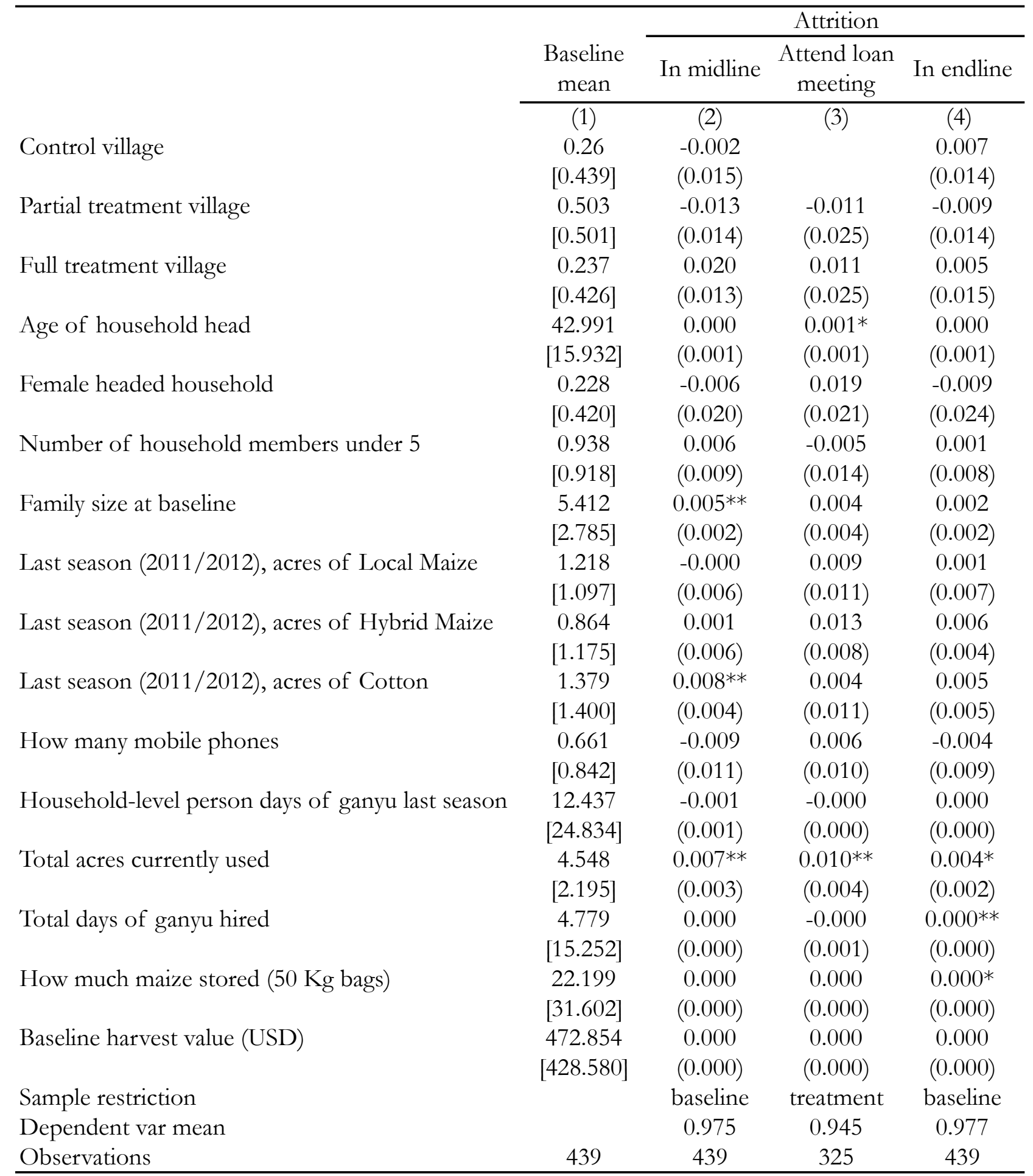

Notes: Column 1 shows means and standard deviations for the full sample at baseline. Columns 2 and 4 show the coefficients from a regression of whether the household was in the midline and endline sample, respectively, on the explanatory variable, with standard errors clustered at the village level. Column 3 shows the same analysis but for whether the household attended theneeting where the loan program was explained, conditional on being in a treatment village. ${ }^{*} \mathrm{p}<0.10 * * \mathrm{p}<0.05$. 
Table 3: Loan take up and repayment

\begin{tabular}{|c|c|c|c|c|c|c|}
\hline \multirow[b]{3}{*}{ Panel A: Sample } & \multicolumn{2}{|c|}{ Control } & \multicolumn{2}{|c|}{ Partial Treatment } & \multicolumn{2}{|c|}{$\underline{\text { Full Treatment }}$} \\
\hline & Number & $\%$ & Number & $\%$ & Number & $\%$ \\
\hline & & & & & & \\
\hline Households & 114 & & 221 & & 104 & \\
\hline Eligible households & 0 & $0 \%$ & 104 & $47 \%$ & 99 & $95 \%$ \\
\hline \multicolumn{7}{|l|}{ Panel B: Take up } \\
\hline Any maize loan & 0 & $0 \%$ & 104 & $100 \%$ & 90 & $91 \%$ \\
\hline Number of bags & 0 & & 2.79 & & 2.62 & \\
\hline \multicolumn{7}{|l|}{ Panel C: Repayment } \\
\hline Loan contracts & 0 & & 104 & & 90 & \\
\hline Some repayment & & & 102 & $98.1 \%$ & 88 & $97.8 \%$ \\
\hline Full repayment & & & 99 & $95.2 \%$ & 87 & $96.7 \%$ \\
\hline Percentage repaid & & & $96.9 \%$ & & $97.7 \%$ & \\
\hline
\end{tabular}


Table 4: Consumption impacts - midline survey

\begin{tabular}{|c|c|c|c|c|c|c|}
\hline \multirow{3}{*}{ Control village mean } & \multicolumn{3}{|c|}{$\begin{array}{c}\text { Number of meals in last } 24 \\
\text { hours }\end{array}$} & \multicolumn{3}{|c|}{ Any missed meals in past week? } \\
\hline & \multicolumn{3}{|c|}{1.736} & \multicolumn{3}{|c|}{0.364} \\
\hline & $(1)$ & $(2)$ & (3) & (4) & $(5)$ & (6) \\
\hline Partial treatment village & $\begin{array}{c}0.0629 \\
(0.0609)\end{array}$ & & & $\begin{array}{l}-0.0599 \\
(0.0659)\end{array}$ & & \\
\hline Full treatment village & $\begin{array}{l}0.213 * * * \\
(0.0594)\end{array}$ & & & $\begin{array}{l}-0.165^{* *} \\
(0.0639)\end{array}$ & & \\
\hline Eligible & & $\begin{array}{l}0.123^{* *} \\
(0.0537)\end{array}$ & & & $\begin{aligned}-0.0766^{*} \\
(0.0435)\end{aligned}$ & \\
\hline Number of bags & & & $\begin{array}{c}0.0456 * * \\
(0.0191)\end{array}$ & & & $\begin{array}{c}-0.0283^{*} \\
(0.0157)\end{array}$ \\
\hline R-squared & 0.110 & 0.102 & 0.103 & 0.092 & 0.083 & 0.084 \\
\hline
\end{tabular}

Notes: $\mathrm{N}=424$. Regressions of midline hunger outcomes on corresponding treatment specifications. Columns 1 and 4 show village level intention to trest regression. Columns 2 and 5 show individual level intention to treat OLS regressions. Columns 3 and 6 the reduced form of an IV regression with individual eligibility as an instrument for the number of bags picked up. All regressions include controls and cluster standard errors at the village level. * $\mathrm{p}<0.10 * * \mathrm{p}<0.05$. 
Table 5: Labor supply impacts - midline survey

Control village mean

Panel A: Village-level ITT
Any ganyu?

$$
0.464
$$

(1)

$$
\begin{gathered}
\text { Days of ganyu } \\
3.055
\end{gathered}
$$

Days of hired ganyu 2.009

(4)

\begin{tabular}{lcccc}
\hline Partial treatment village & -0.0757 & -0.00514 & 2.248 & -0.174 \\
& $(0.0567)$ & $(0.565)$ & $(1.948)$ & $(0.686)$ \\
Full treatment village & $-0.118^{*}$ & $-1.028^{*}$ & 1.407 & 0.158 \\
& $(0.0607)$ & $(0.599)$ & $(1.862)$ & $(0.878)$ \\
R-squared & 0.144 & 0.160 & 0.202 & 0.106
\end{tabular}

Panel B: Individual-level ITT

\begin{tabular}{lcccc}
\hline Eligible & $-0.0835^{* *}$ & -0.260 & 1.578 & -0.562 \\
& $(0.0373)$ & $(0.456)$ & $(1.292)$ & $(0.572)$ \\
R-squared & 0.144 & 0.154 & 0.201 & 0.107
\end{tabular}

\begin{tabular}{|c|c|c|c|c|}
\hline Number of bags & $\begin{array}{c}-0.0309^{* *} \\
(0.0134)\end{array}$ & $\begin{array}{c}-0.0963 \\
(0.164)\end{array}$ & $\begin{array}{c}0.584 \\
(0.464)\end{array}$ & $\begin{array}{l}-0.207 \\
(0.202)\end{array}$ \\
\hline R-squared & 0.146 & 0.155 & 0.201 & 0.111 \\
\hline \multicolumn{5}{|c|}{$\begin{array}{l}\text { Notes: } \mathrm{N}=424 \text { in columns } 1-3 ; \mathrm{N}=418 \text { in column } 4 \text {. Panel } \mathrm{A} \text { shows village level intention to trest } \\
\text { regression. Panel } \mathrm{B} \text { shows individual level intention to treat OLS regressions. Panel } \mathrm{C} \text { shows the } \\
\text { reduced form of an IV regression with individual eligibility as an instrument for the number of bags } \\
\text { picked up. All columns control for covariates shown in Table } 1 \text { and cluster standard errors at the } \\
\text { village level. The outcome variable in column } 1 \text { is a binary variable that equals one if the family } \\
\text { reported any ganyu at midline. Column } 2 \text { reports the corresponding person-days of ganyu reported. } \\
\text { Column } 3 \text { is the person-days of on-farm work and Column } 4 \text { is the person-days of hired ganyu. For } \\
\text { all questions, the recall period is } 2 \text { weeks. }{ }^{*} \mathrm{p}<0.10 * * \mathrm{p}<0.05 \text {. }\end{array}$} \\
\hline
\end{tabular}

\section{Panel C: Number of bags (IV)}


Table 6: Labor supply impacts - endline survey

Control village mean

Panel A: Village-level ITT

Partial treatment village

Full treatment village

Full treatment village

T

$$
\text { Any ganyu? }
$$

$$
0.595
$$

$$
\begin{gathered}
\text { Days of gan } \\
10.96
\end{gathered}
$$

$-0.0825^{*} \quad-0.0746$

$$
(0.0485)
$$$$
\text { (2.833) }
$$$$
-0.0908^{*}
$$$$
-4.340
$$$$
\text { (0.0454) }
$$$$
\text { (2.792) }
$$

0.156

0.214
Days of hired ganyu 3.126

(4)

(4)

R-squared

338.3

(3)

\section{Panel B: Individual-level ITT}

\begin{tabular}{lcccc}
\hline Eligible & $-0.0777^{*}$ & -0.0852 & 9.398 & 0.0273 \\
& $(0.0418)$ & $(2.000)$ & $(16.51)$ & $(0.967)$ \\
R-squared & 0.157 & 0.208 & 0.316 & 0.269
\end{tabular}

\section{Panel C: Number of bags (IV)}

\begin{tabular}{lcccc}
\hline Number of bags & $\begin{array}{c}-0.0286^{*} \\
(0.0151)\end{array}$ & $\begin{array}{c}-0.0314 \\
(0.715)\end{array}$ & $\begin{array}{c}3.461 \\
(5.915)\end{array}$ & $\begin{array}{l}0.0100 \\
(0.346)\end{array}$ \\
& 0.156 & 0.208 & 0.317 & 0.268 \\
\hline
\end{tabular}

Notes: $\mathrm{N}=424$. Panel A shows village level intention to trest regression. Panel B shows individual level intention to treat OLS regressions. Panel C shows the reduced form of an IV regression with individual eligibility as an instrument for the number of bags picked up. All columns control for covariates shown in Table 1 and cluster standard errors at the village level. The outcome variable in column 1 is a binary variable that equals one if the family reported any ganyu for the agricultural season at endline. Column 2 reports the corresponding person-days of ganyu reported. Column 3 is the person-days of on-farm work and Column 4 is the person-days of hired ganyu. For all questions, the recall period is the past agricultural season ( 9 months). ${ }^{*} \mathrm{p}<0.10 * * \mathrm{p}<0.05$. 
Table 7: Wage impacts

\begin{tabular}{|c|c|c|c|c|}
\hline \multirow{3}{*}{ Panel A: Midline } & \multicolumn{4}{|c|}{ Daily self-reported wage (among workers) } \\
\hline & (1) & (2) & (3) & (4) \\
\hline & \multicolumn{2}{|c|}{ Household level } & \multicolumn{2}{|c|}{ Individual level } \\
\hline Partial treatment village & $\begin{array}{l}1.396 \\
(2.116)\end{array}$ & & \multicolumn{2}{|c|}{$\begin{array}{l}-0.515 \\
(1.045)\end{array}$} \\
\hline Full treatment village & $\begin{array}{l}4.666^{*} \\
(2.561)\end{array}$ & & \multicolumn{2}{|l|}{$\begin{array}{l}3.040 \\
(2.364)\end{array}$} \\
\hline Fraction eligible & \multicolumn{3}{|c|}{$\begin{array}{l}4.775^{*} \\
(2.623)\end{array}$} & $\begin{array}{l}3.073 \\
(2.430)\end{array}$ \\
\hline Control village mean & \multicolumn{2}{|c|}{9.65} & \multicolumn{2}{|c|}{7.981} \\
\hline Observations & 154 & 154 & 292 & 292 \\
\hline R-squared & 0.096 & 0.095 & 0.168 & 0.160 \\
\hline \multicolumn{5}{|c|}{ Panel B: Endline (difference in difference) } \\
\hline & \multicolumn{2}{|c|}{ Activity fixed effects } & \multicolumn{2}{|c|}{ Season fixed effects } \\
\hline Partial treatment village & $\begin{array}{l}4.664 \\
(3.631)\end{array}$ & & $\begin{array}{l}4.116 \\
(3.024)\end{array}$ & \\
\hline Full treatment village & $\begin{array}{c}6.437 \\
(4.008)\end{array}$ & & $\begin{array}{c}4.897 \\
(4.824)\end{array}$ & \\
\hline Fraction eligible & & $\begin{array}{c}6.229 \\
(4.387)\end{array}$ & \multicolumn{2}{|r|}{$\begin{array}{c}4.522 \\
(5.070)\end{array}$} \\
\hline Control village mean & \multicolumn{2}{|c|}{18.42} & \multicolumn{2}{|c|}{18.42} \\
\hline Observations & 1,024 & 1,024 & 1,024 & 1,024 \\
\hline R-squared & 0.174 & 0.173 & 0.173 & 0.172 \\
\hline \multicolumn{5}{|c|}{$\begin{array}{l}\text { Notes: Panel A shows the results for average ganyu wages reported at the household level } \\
\text { (columns } 1 \text { and } 2 \text { ) and individual level (columns } 3 \text { and } 4 \text { ). The dependent variable in Panel A } \\
\text { is the average wage received per day of ganyu in the two weeks preceding the midline survey. } \\
\text { Panel B shows difference in difference estimates for ganyu wages reported at baseline and } \\
\text { endline, with village fixed effects. Columns } 1 \text { and } 2 \text { include activity fixed effects for field } \\
\text { preparation, planting, weeding and harvesting. Columns } 3 \text { and } 4 \text { include season fixed effects } \\
\text { and restricts treatment effects to the time period after which loans were announced. All } \\
\text { specifications include the household level controls shown in Table } 1 \text { and cluster standard } \\
\text { errors at the village level. } * \mathrm{p}<0.10^{* *} \mathrm{p}<0.05 \text {. }\end{array}$} \\
\hline
\end{tabular}




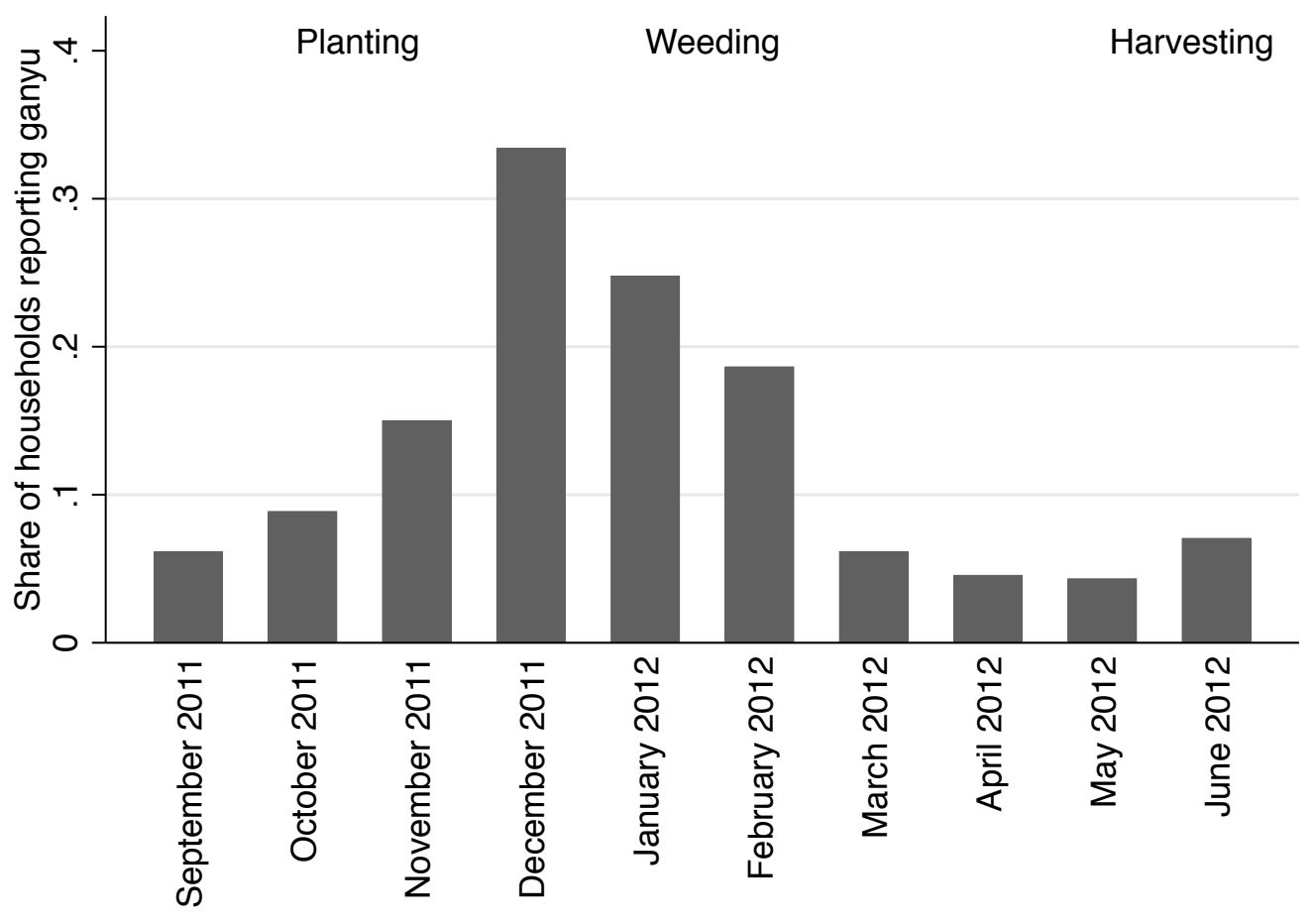

Figure 1: Ganyu labor by month

Notes: Share of households reporting any ganyu labor by month in the agricultural season preceding the baseline survey. 


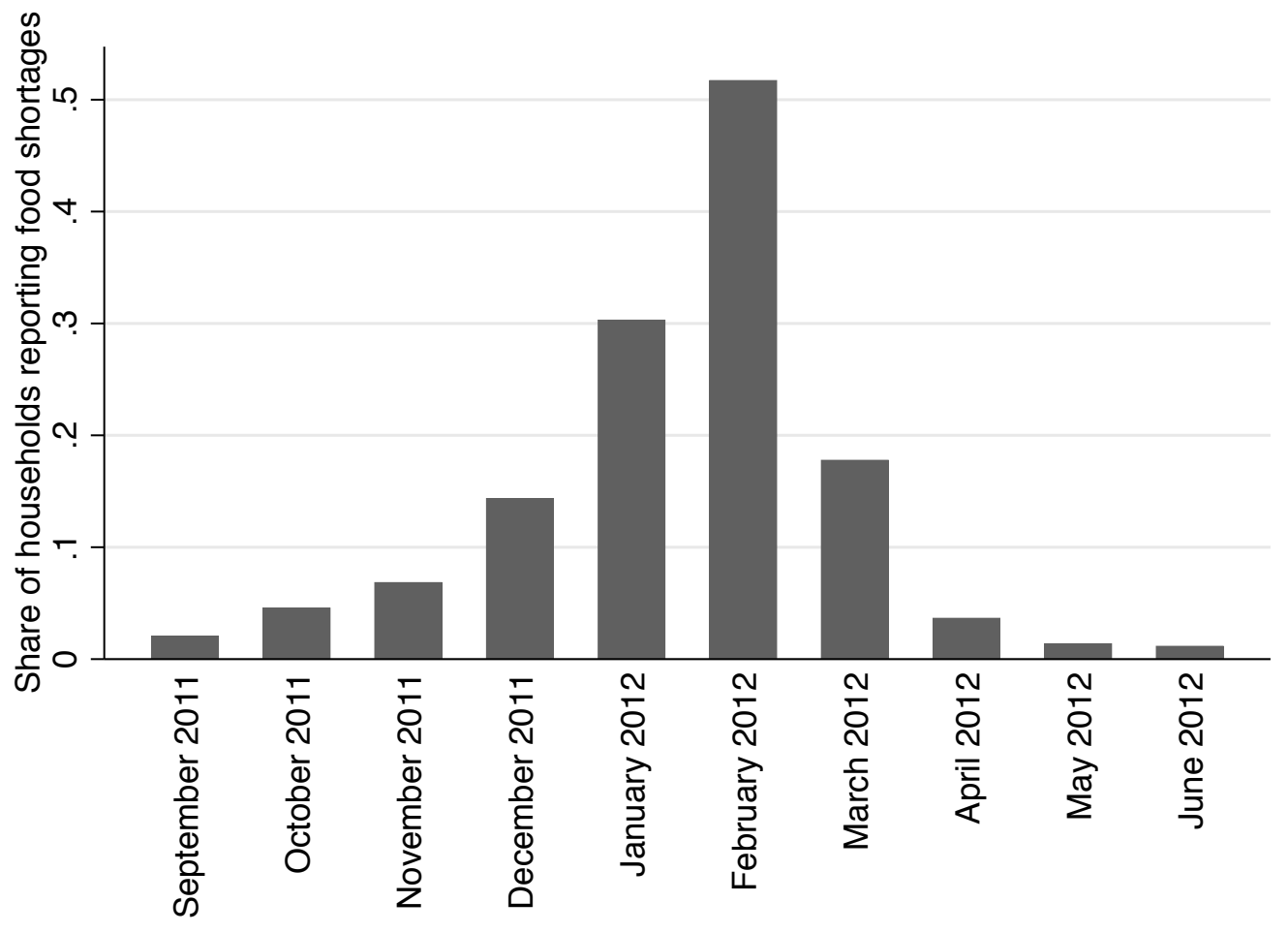

Figure 2: Food shortages by month

Notes: Share of households reporting food shortages by month in the agricultural season preceding the baseline survey. 


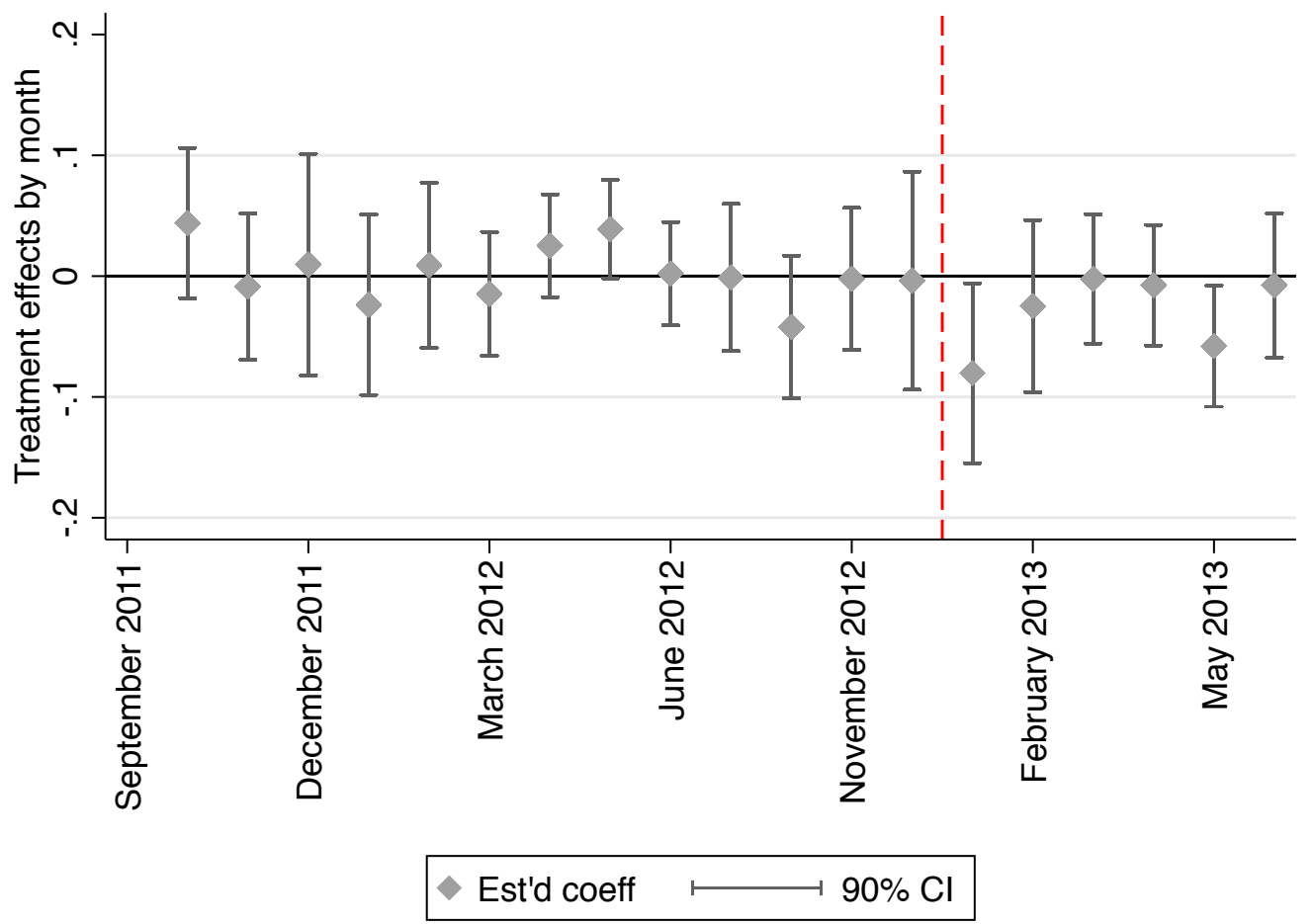

Figure 3: Treatment effects by month

Notes: Month-specific treatment effects from a regression of any household ganyu on treatment-month dummies, with household fixed-effects and standard errors clustered at the village level. Ganyu outcomes measured through household surveys in October 2012 and June 2013. The loan treatment was implemented in January, February and March 2013, with repayment in June 2013. 

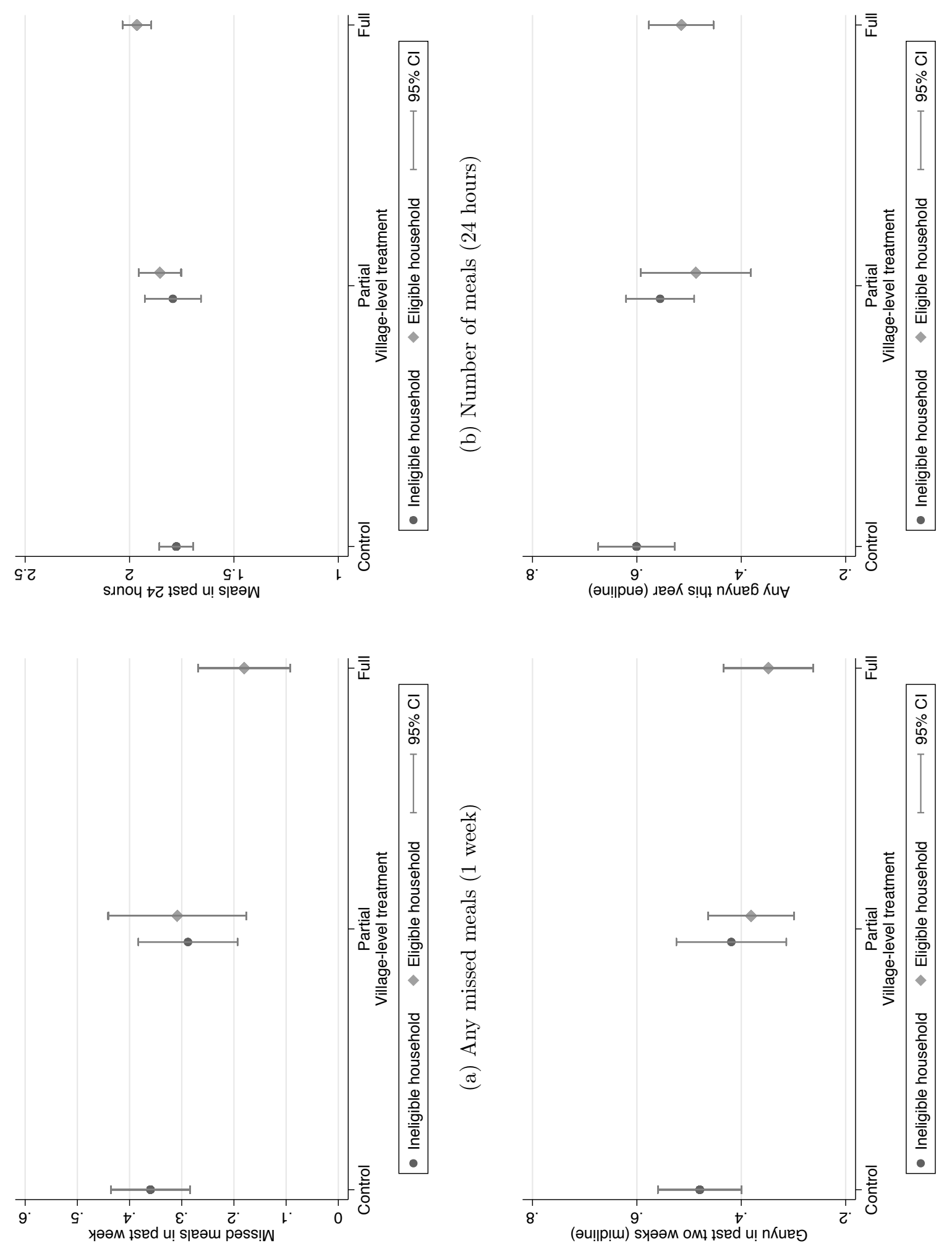

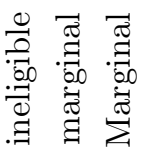

की पु

章

(1) 范 范

क्व

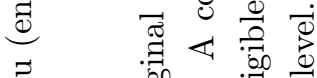

苟 娄

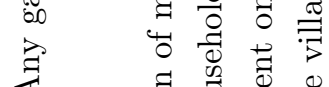

य

(-)

赵

क ज्व

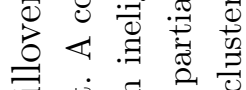

完苞

80 节范

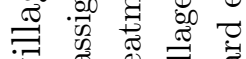

> 5 空

.$\exists$.

\#

$3 \stackrel{\Xi}{\pi}$.

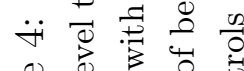

00

社

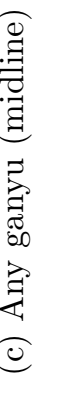

के

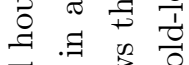

马 50

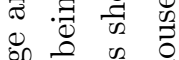

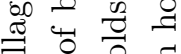

$5+9 . \exists$

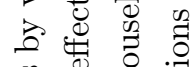

范 00.

进 吾 $\frac{0}{0}$

苗

สี

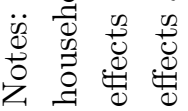


Appendix 


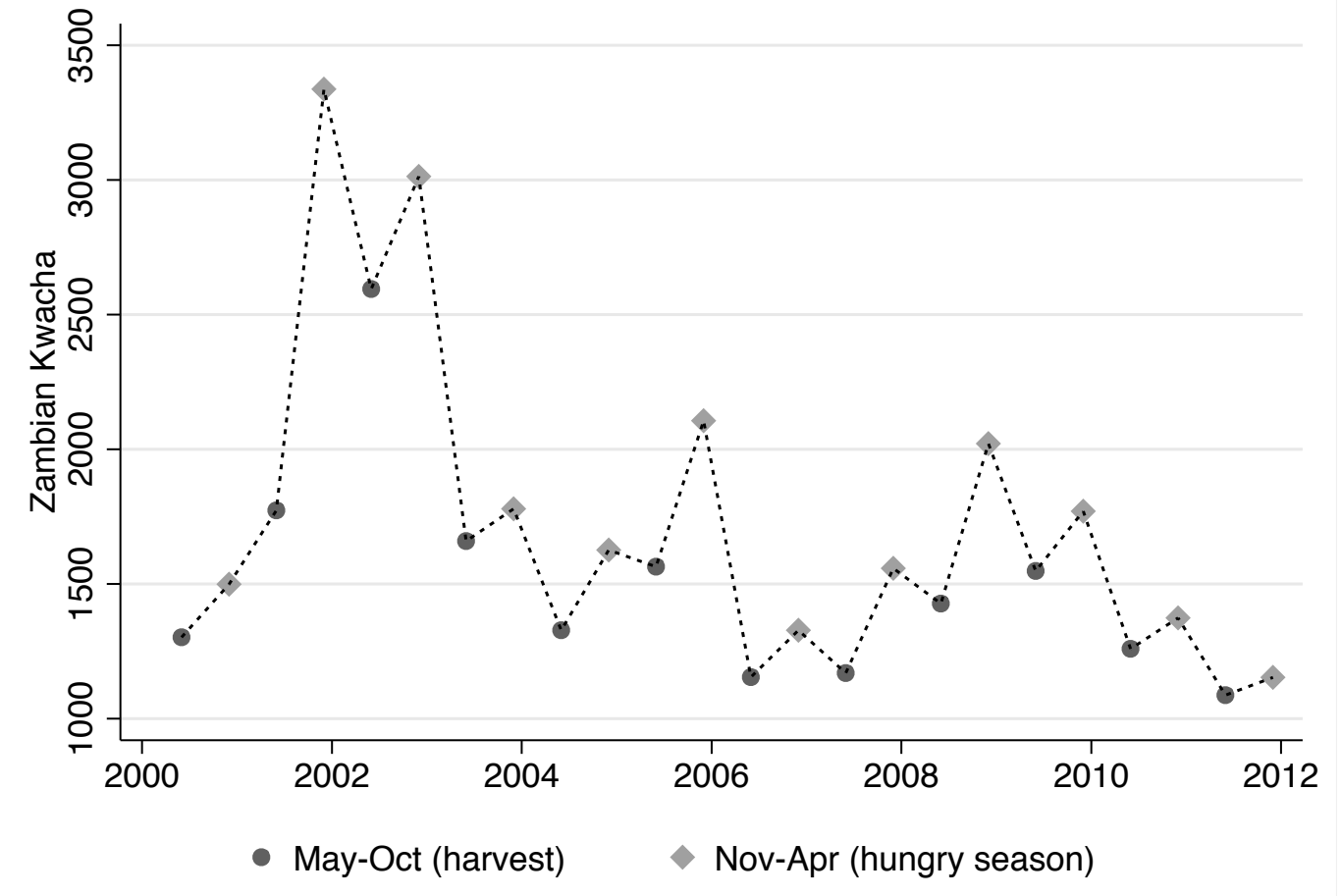

Figure A.1: Seasonal maize prices

Notes: Figure is adapted from data compiled in Ricker-Gilbert (2013), from the Zambian Central Statistics Office and based on district retail prices, averaged across the hungry (lean) and harvest seasons. Prices are in old currency $(1000 \mathrm{ZMK}=1 \mathrm{KR})$ per kilogram. 
Table A.1: Chipata District household characteristics (LCMS 2010)

\begin{tabular}{|c|c|c|c|c|c|c|}
\hline & \multicolumn{3}{|c|}{ All households } & \multicolumn{3}{|c|}{ Rural households only } \\
\hline & $\begin{array}{c}\text { Zambia } \\
\text { excluding } \\
\text { Chipata }\end{array}$ & Chipata & $\begin{array}{c}\text { H0: Equal } \\
\text { means } \\
\text { (p-value) }\end{array}$ & $\begin{array}{c}\text { Zambia } \\
\text { excluding } \\
\text { Chipata }\end{array}$ & Chipata & $\begin{array}{l}\text { H0: Equal } \\
\text { means } \\
\text { (p-value) }\end{array}$ \\
\hline Number of household members & 5.31 & 5.11 & 0.21 & 5.41 & 5.37 & 0.88 \\
\hline Number of rooms & 3.29 & 3.02 & 0.11 & 2.93 & 2.60 & 0.02 \\
\hline Electricity access & 0.33 & 0.22 & 0.64 & 0.07 & 0.02 & 0.00 \\
\hline Private water access & 0.26 & 0.23 & 0.01 & 0.03 & 0.00 & 0.00 \\
\hline Private toilet & 0.71 & 0.59 & 0.14 & 0.65 & 0.52 & 0.00 \\
\hline Grows crops & 0.50 & 0.60 & 0.01 & 0.80 & 0.89 & 0.00 \\
\hline Monthly expenditure in USD & 333.97 & 219.21 & 0.00 & 219.16 & 121.94 & 0.00 \\
\hline Classified as very poor & 0.32 & 0.47 & 0.00 & 0.42 & 0.63 & 0.00 \\
\hline Observations & 18948 & 449 & 19397 & 8243 & 225 & 8468 \\
\hline
\end{tabular}


Table A.2: Labor supply impacts - endline survey, loan months only

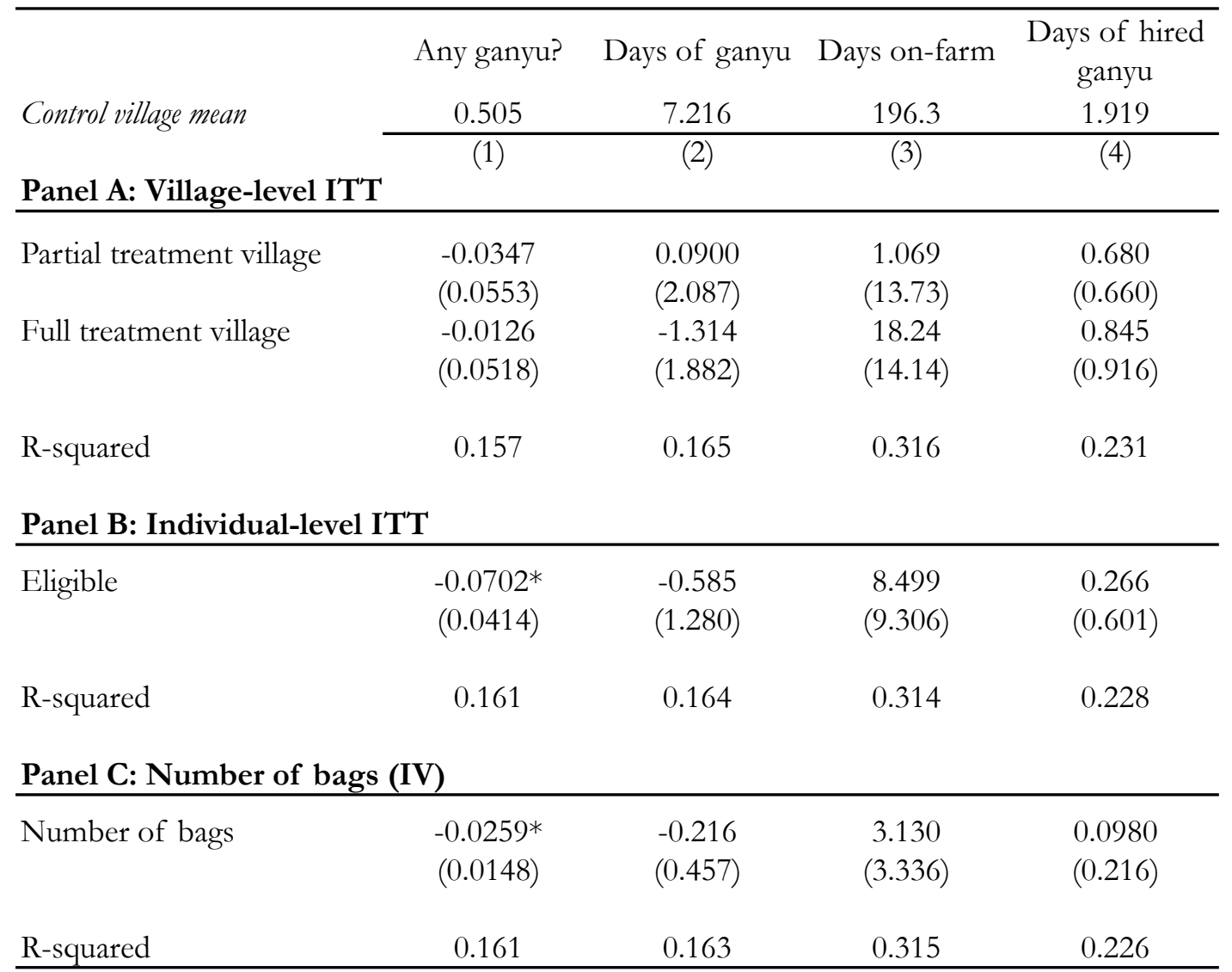

Notes: $\mathrm{N}=424$. Panel A shows village level intention to trest regression. Panel B shows individual level intention to treat OLS regressions. Panel C shows the reduced form of an IV regression with individual eligibility as an instrument for the number of bags picked up. All columns control for covariates shown in Table 1 and cluster standard errors at the village level. The outcome variable in column 1 is a binary variable that equals one if the family reported any ganyu at endline Column 2 reports the corresponding person-days of ganyu reported. Column 3 is the person-days of on-farm work and Column 4 is the person-days of hired ganyu. For all questions, the recall period is the months covered by the loan (Jan-June). ${ }^{*} \mathrm{p}<0.10 * * \mathrm{p}<0.05$. 
Table A.3: Gifts and transfers

\begin{tabular}{lcccc}
\hline & \multicolumn{2}{c}{ Midline } & \multicolumn{2}{c}{ Endline } \\
& $\begin{array}{c}\text { Outgoing gifts } \\
\text { and transfers }\end{array}$ & $\begin{array}{c}\text { Incoming } \\
\text { gifts and } \\
\text { transfers }\end{array}$ & $\begin{array}{c}\text { Outgoing } \\
\text { food gifts }\end{array}$ & $\begin{array}{c}\text { Incoming } \\
\text { food gifts }\end{array}$ \\
\cline { 2 - 5 } Control village mean & 0.336 & 0.236 & 0.658 & 0.387 \\
\cline { 2 - 5 } Partial village: ineligible & $(1)$ & $(2)$ & $(3)$ & $(4)$ \\
& -0.599 & -0.0321 & $-0.113 *$ & -0.0726 \\
Partial village: eligible & $(1.069)$ & $(0.0541)$ & $(0.0592)$ & $(0.0548)$ \\
& 10.43 & $0.342 * * *$ & -0.0450 & -0.0528 \\
Full treatment village & $(10.35)$ & $(0.0768)$ & $(0.0731)$ & $(0.0633)$ \\
& 0.0563 & $0.312 * * *$ & -0.0180 & -0.0387 \\
Observations & $(0.913)$ & $(0.0774)$ & $(0.0858)$ & $(0.0626)$ \\
R-squared & 424 & 424 & 423 & 423 \\
\hline Notes: Regressions of self-reported gifts and transfers at midline (two week recall window) and \\
endline (year recall window). All outcomes are binary and estimated using a linear probability \\
model. Regressions include controls and cluster standard errors at the village level. * p < 0.10 \\
** $<<0.05$.
\end{tabular}

